\title{
10 años de investigación criminológica a través de la REIC
}

\author{
César San Juan Guillén \\ Sociedad Española de Investigación Criminológica
}

\section{Introducción}

Voy corriendo. El tic tac del cronómetro crea una cierta sensación de que llego tarde a algún sitio, como el sastre loco de Alicia en el País de las Maravillas. ISI, Scopus, índice $\mathrm{H}$, in-Recs, etc. marcan un ritmo algo frenético que, en ocasiones, parece amenazar la serenidad, y la capacidad de reflexión que deben caracterizar a un científico. Tengo claro adónde vamos, pero creo que sería bueno detenernos por un momento. Y mirar atrás. Sin otra pretensión que recapitular una parte significativa de lo que se ha hecho en la Revista Española de Investigación Criminológica (REIC). No es evidentemente toda la Criminología que se ha hecho en España, pero la REIC ha ido adquiriendo con el tiempo un determinado perfil que es el que nos gustaría mostrar ahora. Se han defendido en el contexto digital de esta revista algunas conclusiones que, como lector, creo han contribuido de forma significativa a la construcción del conocimiento criminológico, al menos en castellano. Se han empleado recursos metodológicos muy diversos, metodología econométrica (Martín-Segura, 2007), experimental (Marteache, 2010), estudios retrospectivos (Antón, 2009, Díez-Repollés, 2006), asistida con sistemas de información geográfica (Vozmediano, 2006), prospectivos (Varona, 2006), etc. y se han realizado aportaciones novedosas en temas tales como política criminal (Rodriguez, 2003, Díez Repollés, 2008), modelos predictivos (Summers, 2007; Redondo, 2008) o en Psicología Jurídica (Soria, 2008; López, 2009), además de en otros temas clásicos en Criminología y que abordaremos 
más adelante. Este esfuerzo de recapitulación, por otra parte, es una invitación a seguir avanzando en el conocimiento científico del fenómeno criminal, sin prejuicios ni ideas preconcebidas. El objetivo no es otro que aportar herramientas para construir una sociedad basada en la Convivencia, la Libertad y la Tolerancia, precisamente nuestro lema del VIII Congreso Español de Criminología.

\section{Sobre los modelos explicativos del delito y el miedo al delito}

Santiago Redondo (2008) plantea el modelo del Triple Riesgo Delictivo (TRD) con el que realiza un importante esfuerzo de clarificación y ordenación de la compleja etiología de la conducta delictiva. Según este autor, un primer objetivo del modelo TRD es efectuar una re-conceptualización y ordenación parsimoniosa de los factores de riesgo y de protección para el delito en tres fuentes de riesgo con la intención de superar el nivel esencialmente descriptivo de la Criminología, de forma que los factores de riesgo puedan ser estudiados como eventuales variables causales de la conducta antisocial, y no como meros correlatos de la misma. Para ello, los factores de riesgo y de protección son concebidos desde esta perspectiva, no como fuerzas antagónicas (unas de entidad negativa -de riesgo- y otras positiva -de protección- en su influencia sobre el individuo), sino como variables únicas y continuas a las que Redondo denomina dimensiones de riesgo. Cada dimensión de riesgo tendría, como extremos definitorios, pares correlativos de los actuales factores de riesgo y de protección de análoga naturaleza (por ejemplo, impulsividad-autocontrol, amigos antisociales-prosociales, etc.) que delimitarían un gradiente amplio de posibles influencias criminógenas-prosociales. Este autor considera que este cambio de perspectiva es más coherente con la naturaleza dimensional de muchas variables individuales y sociales, que no una concepción maniquea sobre factores radicalmente negativos o positivos. Además, todas las dimensiones de riesgo son agrupadas exhaustivamente en tres fuentes: personales, en el apoyo pro-social recibido por cada sujeto, y en las oportunidades delictivas que se le ofrecen.

Otro objeto de estudio en el ámbito criminológico abordado desde diferentes aproximaciones en la REIC es un fenómeno muy urbano. No es en esta ocasión el hecho delictivo sino el miedo a ser víctima de un hecho delictivo. Así, un mapa de 
criminalidad puede estar basado en tasas objetivas de delincuencia, pero esto no significa que el miedo al delito percibido por los ciudadanos, correlacione con el incremento de las frecuencias de dichas tasas. Así, la investigación sobre el miedo al delito sobre la que profundizaremos en capítulos posteriores ha sido dividida en dos perspectivas generales: del vecindario y situacional (Fernández y Corraliza, 1998). En la perspectiva del vecindario, se describe el miedo como resultado de dinámicas psicosociales de difusión de información sobre problemas delictivos en el área residencial. Desde este punto de vista, adquiere relevancia las valoraciones sobre la presencia y extensión del problema delictivo, así como las noticias concretas sobre sucesos delictivos recientes. También es importante la confianza del individuo en su red de apoyo social informal. En la perspectiva situacional, se describe el miedo al delito como reacción ante una percepción de un peligro actual en un lugar concreto, categorizado como peligroso. Dicha percepción está relacionada con aspectos sociofísicos y configuracionales del propio lugar, así como con el proceso valorativo que lleva a categorizar la situación como peligrosa. Dentro de esta perspectiva, adquiere importancia el deterioro ambiental, la presencia de individuos considerados peligrosos y, por qué no, variables de carácter etológico, relacionadas con la supervivencia en lugares poco adaptativos para la especie, tales como la oscuridad, nocturnidad, dificultad para la localización de vías de escape, etc.

Fernández (2008) plantea seis hipótesis generales para explicar este fenómeno que pasamos a detallar a continuación:

\section{La hipótesis del extraño}

Es una idea antigua del sociólogo George Simmel (en Wolf, 1950), cuyos escritos mezclan un lenguaje metafórico sugerente con cierto tinte visionario. La idea del extraño refleja una de las características que han configurado la personalidad del habitante de nuestras ciudades: nadie conoce a nadie. Tenemos muchas relaciones diarias, muchas interacciones en muchos espacios de la ciudad, incluso podemos estabilizar una relación, hacerla continua, pero nunca tenemos un conocimiento profundo ni certeza sobre quién es la persona con la que estamos hablando.

La cuestión, en fin, es el papel de este desconocimiento mutuo para entender por qué tengo expectativas de ser víctima de un delito en una situación concreta, en la que 
carezco de claves para descifrar el comportamiento del otro, o las claves son ambiguas y no sé por dónde va a salir la situación, no sé qué va a pasar, no sé quién es esta persona que me mira o camina hacia mí, no sé quién es esta persona con la que ahora me cruzo y que me inspira sentimientos de inseguridad y peligro.

\section{La hipótesis psicológica}

Frente al residente de asentamientos tradicionales en comunidades reducidas, el habitante de las ciudades está acostumbrado a lidiar diariamente con una multitud de interacciones, situaciones y personas diferentes que demandan su atención; con situaciones concretas en las que hay una variedad incontrolable e imposible de asumir de luces, colores, sonidos, imágenes, letreros, personas que cruzan, todo en el mismo momento o en rápida sucesión. Claro, no se puede estar atento a todo.

Es decir, cómo no nos sentimos de ninguna manera responsables de ayudar o de atender a un desconocido que lo requiere porque está viviendo una situación de amenaza (alguien le roba o le agrade en la vía pública), quizá socialmente rechazable (un indigente pidiendo ayuda), quizá sólo alguien ajeno que cae cerca de nosotros víctima de un problema de salud. Sentimos que lo que pase a estas personas no depende de nosotros, es posible que pensemos que no podemos hacer nada o que ya acudirán los servicios públicos dedicados a estas cuestiones (policía, urgencias).

\section{La hipótesis económica}

Los factores económicos han tenido una gran relevancia en el desarrollo de la teoría urbana, a pesar de que los clásicos fueran criticados en su momento por sugerir cierto determinismo aparentemente burdo. Su importancia se refleja en que este tipo de planteamiento no se ha abandonado con los años, sino que encuentra importantes continuadores en autores de gran relevancia. Una de sus ideas básicas es que los factores económicos condicionan o determinan de algún modo la distribución de los grupos sociales dentro de la ciudad, e incluso la forma de la ciudad.

\section{La hipótesis ecológica}

Aún dentro de la gran urbe, el barrio se convierte en una unidad social intermedia, próxima a la experiencia de convivencia cara a cara de la comunidad tradicional, porque 
en el barrio todavía no hemos perdido este tipo de relaciones cercanas, nos conocemos, generamos normas, y el control social en este caso no requiere del apoyo de un control formal, al menos no tan presente. Fuera de mi barrio, en una situación potencial de peligro, necesito la presencia del orden público para sentirme seguro; en mi barrio, la mera presencia de las personas, mi conocimiento de los lugares, la proximidad a mi casa, suponen elementos tranquilizadores por sí solos (Fernández-Ramírez y Corraliza, 1998; San Juan, Vergara y Germán, 2005). ¿Cuál es la solución?: crear y afianzar las redes sociales para potenciar los mecanismos del control social informal.

El diseño antidelito amplía su base teórica con el discurso de la territorialidad (Taylor, 1987).

En esta línea ha realizado aportaciones interesantes en cuanto al empleo de Sistemas de Información Geográfica en el estudio de miedo al delito (Vozmediano \& San Juan, 2006). Uno de los resultados más significativos de su estudio ha sido confirmar la denominada paradoja del miedo al delito. Así, frente a la no relación del miedo al delito con los datos de criminalidad objetiva, las variables psico-socio-ambientales incluidas en el estudio sugieren que la percepción del espacio físico y los vecinos, así como la creencias compartidas sobre la efectividad de la justicia y el papel del ayuntamiento en garantizar la seguridad, podrían estar jugando un papel en la génesis y mantenimiento del miedo al delito.

\section{La hipótesis racionalista}

La perspectiva racionalista está presente desde Max Weber (1972) en buena parte de las ciencias sociales y la psicología, suponiendo que sólo podemos anticiparnos y prever lo que hará una persona cuando actúa de manera racional, es decir, cuando se comporta de acuerdo con un plan de actuación previsto para conseguir un objetivo deseado. Está en la base del concepto de escenario de conducta, ya que el programa del escenario reúne los planes de comportamiento intencionales en el lugar, y es una de las críticas que recibía la ecopsicología de Barker (1968), puesto que el rango de comportamiento potencialmente analizable se limitada a los comportamientos dirigidos a una meta (Kaminski, 1983). También las actividades del delito y las cuestiones de la inseguridad forman parte de un cierto racionalismo, tal como se deriva de la idea de transmisión cultural planteada por Clifford Shaw y H. McKey (1942), los criminólogos de la Escuela de Chicago. Un delincuente no es un loco (que serían un porcentaje ínfimo, los 
que llamaron la atención de Lombroso), sino un profesional de la delincuencia, una persona que tiene una cultura especial bien aprendida, que sabe cómo se comente un robo, cómo funciona el tráfico de drogas o el negocio de la trata de blancas.

\section{La hipótesis narrativa}

En fin, cuando pensamos en la delincuencia y la inseguridad, también nuestros argumentos y nuestros datos forman parte de discursos sociales que responden a presiones de distintos grupos que tienen un componente político, muchas veces de manera sutil, mas nunca inocente, dados los intereses en juego. En este sentido Cubells \& Iñiguez (2008) mostraremos cómo los "hechos" considerados "brutos" por la institución jurídica adquieren materialidad y estatuto de "hecho jurídico" a partir de las prácticas que se desarrollan en el seno de la propia comunidad. El análisis realizado revela que los 'hechos brutos' son el resultado de un proceso de construcción discursiva. No existe una manera objetiva de describir hechos, de modo que es falaz sostener el acceso a los mismos 'tal y como éstos ocurrieron". Así, la única forma de acercarse a los hechos es a través de un proceso de re-construcción que se realiza mediante prácticas lingüísticas.

Desde este punto de vista, Swaaningen (2005) plantea que en la literatura criminológica internacional Holanda es generalmente caracterizado como un país tolerante y liberal: permisivo hacia muchos vicios, amistoso con los extranjeros y bendecido con un clima penal suave. Todo esto se percibe ahora como la indulgencia malentendida del pasado, indulgencia que nos ha llevado a una situación con problemas que, según este autor, se nos van de las manos. Con este supuesto pasado presentado como un error, Holanda en los últimos años se ha convertido en un país confundido, intolerante, punitivo y que está obsesionado con la seguridad. Pero esto parece ser el reflejo de un estado de opinión en toda Europa. En este respecto, anticipa que las ideas inclusivas sobre prevención local del delito se acaban convirtiendo en políticas excluyentes de inseguridad ciudadana. El aumento del racismo contra minorías islámicas, que se desarrolló tras el ataque a las Torres Gemelas en Nueva York y el asesinato de un líder populista de derechas y un director de cine en Ámsterdam, ha sido un catalizador importante del nacimiento de una cultura del control guiada por el pánico. Otros factores que hay que considerar son el papel de los políticos populistas y los periodistas que en la actualidad actúan como 
"traficantes del miedo" y en los problemas de identidad que la "gente ordinaria" confronta como resultado de la globalización de la economía y la erosión del sector público.

Para este autor, probablemente la cuestión más interesante para los criminólogos sea hasta qué punto la gestión y administración pública de la seguridad se ha convertido en un tema de nosotros, los ciudadanos que cumplimos la ley, contra ellos, los mendigos, drogodependientes, prostitutas de calle, bandas juveniles y especialmente minorías étnicas (musulmanas), y cuáles son los posibles contra efectos de esta tendencia (van Swaaningen, 2007). Así, el lenguaje en el que se actualmente se formulan los proyectos políticos definitivamente ha cambiado. Los matices y las bases científicas son reemplazadas por proclamas sobre "la tolerancia cero", "gamberros", "marines" y demás, así como por la retórica encendida de lo simplista del tipo "nosotros contra ellos". El punto clave para la investigación es en qué medida estos cambios en el plano discursivo son de hecho el reflejo de prácticas sustantivas. El planteamiento central de los análisis de Garland de una "cultura del control" se refleja claramente en el caso holandés, y muy especialmente en Rótterdam (van Swaaningen, 2004).

\section{Delincuencia y justicia juvenil}

Fernández, Bartolomé, Rechea \& Megías (2009) defienden que la opinión pública internacional publicita un aumento significativo de la delincuencia juvenil en las últimas décadas y que se trata de una delincuencia más violenta, en la que las jóvenes tienen una mayor participación y que no culmina hasta los últimos años de la adolescencia. Para estas autoras, en España existe también esta percepción social y mediática sobre la delincuencia juvenil. Pero el conocimiento de la evolución y tendencia de estas conductas en nuestros jóvenes es pobre y muy parcial. En su trabajo describen la evolución de la conducta antisocial y delictiva juvenil en el periodo 1992-2006, a través del análisis de dos tipos de datos distintos y complementarios: datos de auto-informe y de diversas instancias oficiales. Los resultados de su trabajo muestran una tendencia estable en este periodo, con pequeñas subidas y bajadas en conductas concretas. En este sentido, hay un tipo de conductas en que sí se ha producido un claro aumento: el consumo y venta de drogas ilegales. La tendencia encontrada respecto al consumo coincide con la encontrada por el Observatorio Español sobre Drogas para el periodo 
1994-2006 y se considera el resultado de un proceso de normalización tanto en el consumo como en su percepción social. Sin embargo, conviene matizar que hay indicadores de que la tendencia podría estar empezando a cambiar y tanto el interés por las drogas como los efectos indeseables sobre la salud de los jóvenes podrían estar descendiendo en la actualidad (Comas, 2008).

En todo caso, como bien señalan los investigadores de la carrera criminal, sería necesario realizar análisis que combinaran datos oficiales y de autoinforme de los mismos individuos (Piquero, Farrington, y Blumstein, 2003); además, sería muy enriquecedor estudiar el proceso de toma de decisiones que realizan los operadores jurídicos del sistema de justicia juvenil cuando responden a la conducta delictiva de los jóvenes y menores para conocer mejor las estrategias de judicialización actuales.

Además de las metodologías citadas, Rodgers (2004) propone estrategias quizás más comprometidas en el estudio de la conducta antisocial como es la observación participante. El planteamiento es analizado por este autor través de la descripción y consideración de las experiencias del autor al ser iniciado en una pandilla juvenil en una ciudad de Nicaragua, experiencias que plantean una serie de cuestiones sobre la naturaleza de la práctica de la investigación etnográfica en general y de la violencia en particular.

Por otra parte, la investigación sobre la conducta antisocial en jóvenes también se ha ocupado de las diferencias de género. Bartolomé, Montañés, Rechea \& Montañes (2009), consideran que la investigación sobre conducta antisocial y violenta en adolescentes muestra de forma persistente que los chicos conforman el grupo de riesgo para desarrollar una carrera delictiva seria y, especialmente, violenta. Dos posibles hipótesis se han planteado para explicar este hecho: a) que chicas y chicos estén diferencialmente expuestos a los mismos factores de riesgo/protección y b) que el efecto de esos factores sea diferente en cada grupo. Este trabajo tiene como objetivo explorar las semejanzas y diferencias de comportamiento entre chicas y chicos adolescentes y poner a prueba las dos explicaciones señaladas con respecto a diversos factores de protección considerados relevantes en la literatura. Para ello se utilizan los datos recabados a través de autoinforme entre 642 adolescentes escolarizados de Albacete. Los resultados muestran que, aunque las chicas están más expuestas a ciertos factores de protección. Fundamentalmente, están más supervisadas por sus padres y muestran vínculos más fuertes con amigos pro sociales. Además, tienen mayor interés en seguir 
estudiando. Esto es lo esperado de acuerdo con las teorías de control social, esto no explica por completo su menor tendencia a la violencia. Por otro lado, al contrario de lo esperado, el efecto protector de los factores parece ser mayor en los chicos.

La literatura se está haciendo eco de que existen tantas contradicciones en los resultados obtenidos sobre la cuestión genero/delincuencia, que es necesario mejorar el conocimiento sobre las chicas, pero también cambiar como se plantean las investigaciones (Bartolome, 2001; Chapple et al., 2005; Weiler, 1999). A pesar de ello, si merece la pena destacar un importante efecto en las chicas de los factores de protección relacionados con tener objetivos de futuro y tener planes de seguir estudiando. Según estas autoras, estas podrían ser cuestiones a tener especialmente en cuenta a la hora de diseñar programas de intervención y prevención dirigidos a la conducta violenta en las chicas. En cambio, la búsqueda de apoyo social ante los problemas, una estrategia más habitual en mujeres, no les protege de la conducta antisocial en estas edades, lo que puede estar relacionado con que el apoyo que buscan es el de los amigos o pareja, con los que comparten estilo de comportamiento en gran medida.

Tratamiento educativo vs. sancionador.

Cuando en el año 2000 se publicó la LO 5/2000 de 12 de enero, reguladora de la responsabilidad penal de los menores, se presentó como el texto definitivo que habría de devolver la estabilidad al ámbito de la política criminal española de jóvenes y menores. Sin embargo, cuando está a punto de acabar el año en el que se celebran los cinco años de vigencia de la Ley, se ultima la que es ya la cuarta reforma que el sistema de justicia de menores español ha sufrido desde entonces.

Tal y como ponen de manifiesto Fernández \& Rechea (2006), aunque los datos oficiales sobre delincuencia juvenil no evidencian un aumento significativo de las cifras, el legislador, tal y como ha declarado en el Proyecto de Ley, sí lo cree y con la intención de frenar ese aumento ha previsto modificaciones legislativas. Esos cambios han supuesto la adopción de nuevos criterios para la aplicación de las medidas y la incorporación definitiva de la víctima a un sistema que debería estar presidido exclusivamente por el interés del menor. Por otra parte, los resultados de la aplicación 
práctica de la Ley presentados en este artículo permiten concluir que las tendencias están cambiando y que la práctica judicial durante estos cinco años ha acabado contaminándose del clima más punitivo que parece prevalecer en toda la política criminal del país.

En el mismo sentido se expresan Bernuz, Fernández \& Pérez (2009) cuando analizan la medida de libertad vigilada. Estas autoras cuestionan si realmente la medida de Libertad Vigilada consigue individualizar la respuesta que se proporciona a los menores infractores, tanto a las circunstancias psicosociales del menor cuando este comete el delito, como a la evolución del mismo a lo largo de la ejecución de la medida. Los resultados de la investigación sugieren que a pesar de la respuesta especial y distinta que se da en la justicia de menores que pretende valorar las circunstancias psicosociales del menor, se aprecia cierta homogeneidad en las intervenciones.

\section{Problemas asociados}

Los señalados por Martín (2008) en relación a los jóvenes que teniendo menos de 21 años están cumpliendo condena en centros penitenciarios de adultos. Este autor destaca el bajo nivel académico, el abandono escolar prematuro, el alto porcentaje de consumidores de drogas, así como la escasa o nula cualificación profesional de la población estudiada.

Mateu-Gelabert (2004) nos regala su experiencia de cinco años de trabajo de campo en una comunidad inmigrante de la ciudad de Nueva York para describir cómo la distancia generacional que separa a los adolescentes inmigrantes de sus padres, es ampliada por el proceso de inmigración. La experiencia migratoria y la separación generacional llevan a los adolescentes que se sienten amenazados a buscar protección en bandas. Mientras que anteriores investigaciones han explicado la violencia adolescente entre inmigrantes como un producto de la alienación cultural, este informe sugiere que gran parte de la violencia entre estos adolescentes es una respuesta pragmática a las condiciones de inseguridad del vecindario, y que las políticas de prevención debe tener por objetivo garantizar la seguridad de los adolescentes.

Las características del barrio son de gran importancia para comprender el proceso de inmigración y cómo se relaciona con la violencia. Los adolescentes recién llegados deben adaptarse rápidamente para evitar ser víctimas, y a menudo adoptan comportamientos violentos como una forma de adaptarse al nuevo entorno. Los 
adolescentes de segunda generación crecen en este entorno, en el que se utiliza la violencia como medio de conseguir y mantener el respeto de la manzana. Representar a la manzana de uno es parte de la formación de la identidad de los adolescentes. La manzana ofrece seguridad, define las relaciones sociales apropiadas e identifica quienes son los enemigos. Para muchos adolescentes, esta afiliación es claramente contextual puesto que cuando van creciendo y asisten al instituto fuera del entorno violento de su vecindario, su relación con los grupos violentos disminuye. Muchos incluso cambian su visión, considerando este tipo de violencia como circunscrita al barrio de residencia e infantil. Otra prueba de esta tesis que sostiene que la identificación con grupos violentos es resultado de una necesidad contextual son las experiencias de los nuevos inmigrantes. Mientras asistían a la escuela primaria, no se relacionaban con bandas, pero lo hicieron en el instituto. Después de recibir amenazas entablaron amistan con miembros una banda y se unieron a ella, como fuente de protección.

Para prevenir que los adolescentes inmigrantes se unan a grupos violentos este autor cree que es necesario ofrecerles entornos seguros en los que puedan adaptarse a las nuevas costumbres de EEUU sin tener que recurrir a estos grupos en busca de seguridad.

Se pueden identificar, en fin, retos muy interesantes en el ámbito de la delincuencia juvenil no solo relacionados con los asuntos citados. También queda mucho camino por recorrer en términos de modelos explicativos, prevención e intervención con respecto a los menores que cometen delitos antes de los 14 años (Bernuz, 2009).

\section{Política criminal y tratamiento penitenciario}

Decíamos en la recensión del magnífico libro de Redondo "In-tolerancia cero" (Gimenez-Salinas \& San Juan, 2009) que el Estado diseña una respuesta punitiva dura, demagógicamente llamativa y con una filosofía puramente cortoplacista. La justicia se convierte en una especie de "Fast Law", que no hace referencia precisamente a una justicia ágil y eficaz, sino a una justicia que, al igual que la Fast Food, el pueblo pueda devorar en poco tiempo para aplacar cuanto antes la alarma social inflacionistamente generada. Nuevamente puede resultar útil la metáfora del carácter aceitoso de esta Fast Law ya que su oleaginoso colesterol es identificable en innumerables análisis 
informativos y tertulianos que se ofrecen en la televisión sobre las explicaciones de la delincuencia y su tratamiento. Pero como señala Redondo en la obra citada, “...la delincuencia no es, con carácter general, una suerte de enfermedad o patología que pueda resolverse mediante un fármaco, ya sea administrado en grageas o en inyectables. Aunque es humano anhelar un remedio total y definitivo para la agresión y la delincuencia, tal remedio no existe".

Esto es así en un contexto en el que la evolución de la delincuencia común en España, hallada a través de las encuestas de victimización, presenta una tendencia descendente entre 1989 y 2008. De hecho, la tasa de victimización hallada para los últimos cinco años anteriores al pase de cada una de las tres encuestas de victimización realizadas desde la primera de esas fechas ha descendido en casi 9 puntos, y la del último año ha bajado en algo más de 10. Por su parte, la tasa de delitos totales subió ligeramente entre 2005 y 2008, aunque no tanto como lo que bajó entre 1989 y 2005 (García España et al., 2010) lo que parece cuestionar la idea de que vivimos en una sociedad cada vez más violenta (Mucchielli, 2010).

El diagnóstico que elabora Cid (2008) lo resume en los siguientes tres aspectos a) el C.P. de 1995 supuso un gran incremento punitivo -al elevar las penas nominales de algunos delitos y eliminar la redención de penas- y este factor, por sí sólo, explica el crecimiento de la población reclusa entre 1996-2006 de casi 20.000 personas, lo que supone un aumento del $43 \%$ en términos absolutos; b) la nueva regulación de la suspensión de la pena, y el uso que han hecho los/as jueces/zas de ella, ha contribuido de manera poderosa a la reducción del número de entradas en prisión; no obstante, ha faltado un desarrollo de los mecanismos de sustitución de la pena, aplicándose de manera muy limitada las vías intermedias entre prisión y suspensión de la pena para personas con antecedentes penales, que podría haber reducido ulteriormente las entradas en prisión (López, 2003); c) la progresiva reducción del número de libertades condicionales concedidas es un reflejo de la nueva situación punitiva basada en el alargamiento de las penas, sin que durante estos años haya existido una política dirigida a incrementar el porcentaje de personas que finalizan su condena en libertad condicional, que hubiera podido mitigar las exigencias del nuevo marco punitivo.

Con este diagnóstico Cid (2008) plantea las siguientes propuestas: 
a) La propuesta de ampliar las posibilidades de imponer penas alternativas no sólo pretende evitar entradas innecesarias en la prisión sino también reducir las mayores tasas de reincidencia de las personas condenadas a penas cortas de prisión, comparativamente a las condenadas a penas alternativas. Para ello se diseña un sistema de penas alternativas capaz de afrontar las necesidades criminógeneas de las personas en los casos en que sea necesario.

b) La reducción de la duración efectiva de las condenas no sólo trata de limitar los costes humanos y económicos del encarcelamiento, sino que el desarrollo de programas de reinserción en el periodo de transición entre la privación de libertad y la libertad definitiva se consiga reducir la tasa de reincidencia de las personas encarceladas (Luque, Ferrer y Cadevila 2004). Contrariamente a lo que suele presumirse en círculos no criminológicos, no es el cumplimiento efectivo de la condena lo que va a proteger a la sociedad de futura delincuencia, sino que lo que tiene mayor posibilidad de conseguirlo es un regreso a la comunidad apoyado socialmente, realizado a través, principalmente, de los mecanismos del tercer grado y de la libertad condicional (Cid, 2010)

c) El apoyo a programas de rehabilitación dentro de la prisión que puedan abordar algunas necesidades criminógenas de la persona, los cuales deberán ir vinculados a programas en el exterior, no debe ser visto como algo que sólo favorece a la propia persona condenada, en cuanto le ayuda a superar problemas, sino que debe también ser valorado por el beneficio social que reporta al poderse reducir la tasa de reincidencia.

En la misma línea plantean propuestas Guimera (2005) en el ámbito de lo que conocemos como justicia reparadora, Larrauri (2010) con los programas formativos en los casos de violencia de género,

Lo que subyace a la línea argumental expuesta es el escasísimo efecto rehabilitador de la cárcel. Podría decirse que el recluso, más que vivir en la cárcel, acaba viviendo la cárcel (Smyth y Ivanoff, 1994; Wright, K. ,1993; Ellis, 1989). Así pues cabe preguntarse, ¿Realmente existe una buena cárcel? Veitch y Arkkelin (1995) hacen referencia en su manual de Psicología Ambiental a la relación de modelos de privación 
de libertad basados, cada uno de ellos, en los objetivos que se pretenden con la reclusión. Estos son la incapacitación, la reforma, la rehabilitación, la retribución, la restitución, la reeducación y la integración. En función de la filosofía pretendida, se aportan soluciones arquitectónicas diversas. En este sentido, y con respecto a su estructura arquitectónica, Valverde (1991) cree conveniente distinguir entre los aspectos referidos a la cantidad de espacio y aquellos referidos a la calidad de espacio. Si todos necesitamos un espacio personal, íntimo, en una institución total como es la cárcel, los espacios personales son fundamentales para mantener una cierta salud mental. Lamentablemente, no se trata éste de un aspecto sobre el que se repare a la hora de diseñar un centro penitenciario (Redondo, Roca, Pérez y Sánchez, 1990). El hacinamiento o, en todo caso, la sobrepoblación, es uno de los problemas más graves en casi todas las cárceles, constituyendo un decisivo factor de riesgo para la salud mental del preso y la convivencia en el centro (Wener \& Keys, 2006). Según una investigación de Cox, Paulus, y McCain (1984), se sabe que las prisiones con elevado número de internos presentan una proporción mayor de muertes violentas, suicidios, infracciones disciplinarias y comportamientos psicopatológicos, las celdas dobles, triples, y los dormitorios colectivos provocan cuadros de ansiedad, miedo o agresividad.

Por otra parte, y de cara al diseño de espacios, también deben tenerse en cuenta algunas situaciones especiales, como es el caso de las madres reclusas que viven con sus hijos en prisión. Se trata de una situación extraordinaria que el establecimiento penitenciario debe considerar de tal forma que garantice el normal desarrollo afectivo y educativo de los menores. En un estudio de Jiménez (2002) realizado en centros penitenciarios españoles se constata que la calidad de la estimulación en el escenario educativo familiar es extraordinariamente baja y que las guarderías apenas superan el mínimo de calidad aceptable. A esto debe añadirse que no en todas las comunidades existen centros penitenciarios con módulos adaptados a reclusas con hijos, por lo que deben ser trasladadas fuera de su entorno social, añadiendo una dificultad más a su supuesto proceso de rehabilitación (Manzanos, 2003).

En el mismo sentido debemos referirnos a los espacios destinados al vis-a-vis. En muchos casos se trata de espacios en los que se prima la seguridad y la despersonalización del diseño, evitando en muchas ocasiones cualquier elemento que haga más confortable las relaciones sexuales que, además, son programadas. 
Es obvio que muchas veces no se contemplan estas consideraciones cuando se diseña una cárcel y se prima de manera exclusiva su función de contención. Por esta y otras razones no resulta fácil sobrellevar un periodo, a veces muy largo, de reclusión y la cárcel suele ser el primer desencadenante de lo que se denomina la carrera delincuente.

En este sentido, la prevención de la reincidencia debe estar dirigida no solo a la intervención de variables estructurales o ambientales fuera de la cárcel, sino, y de modo prioritario, a la cárcel misma. El sistema penitenciario actual basado en la extrema rigidez de normas y en una relación vertical entre la institución cerrada y sus usuarios llega a "infantilizar" el comportamiento del recluso (Benque, 1990). La ausencia de conciencia de responsabilidad en la comisión del delito es una de las muchas e indeseables consecuencias de ese proceso.

Desde esta perspectiva, las condiciones en las que una cárcel puede favorecer la reinserción social del recluso son realmente dudosas. Propiciar la adaptación social en un medio sin sociedad es una tarea harto difícil. Sin embargo, actualmente, debido a factores políticos y sociales la pena consistente en la privación de libertad parece ser la única vía existente. Desde este punto de vista y siendo realistas, el primer paso para conseguir una mejora en los resultados, es desarrollar unos tratamientos serios y bien estudiados (Martínez y Arróspide, 1996, p.102). Podemos concluir que, siquiera sea, podemos mejorar el ambiente de una prisión que Insel y Moos ,( citados por Del Pozo (1987)), han definido como "aquel que facilita que las decisiones críticas sobre los cambios ambientales estén en manos de la gente que actúa dentro del mismo". Debemos tener en cuenta que en algunos países asiáticos, incluido Japón, a pesar de aglutinar sociedades de una alta cohesión comunitaria, las cárceles disponen de unos durísimos regímenes sancionadores que quizás podrían explicarse desde el "efecto de la oveja negra", pero que sitúan a los centros de reclusión de nuestro contexto lejos de esos signos que apunta Sykes (1987, p.585) tales como el anonimato del uniforme, el empleo de un número en lugar del nombre o la cabeza rapada. En todo caso, esa mejora a la que se hacía referencia exige, según Moreno (1997), la creación de canales de comunicación entre los internos y los funcionarios, y que se mantengan día a día, porque como apuntan Sancha y García (1987), el régimen de vida diario de 
una institución es más decisivo que los programas especiales respecto a la reinserción social. 


\section{Referencias}

Antón, L. \& Larrauri, E. (2009). Violencia de género ocasional: Un análisis de las penas ejecutadas. Revista Española de Investigación Criminológica, 7.

Barker, R.G. (1968). Ecological psychology: Concepts and methods for studying the environment of human behavior. Stanford, CA: Stanford University Press.

Bartolome, R. (2001). Delincuencia juvenil femenina. Tesis Doctoral UCLM no publicada.

Bartolomé, R., Montañés, M., Rechea, C \& Montañés, J. (2009). Los factores de protección frente a la conducta antisocial : ¿explican las diferencias en violencia entre chicas y chicos ?. Revista Española de Investigación Criminológica, 7, 115.

Benque, C. (1990). Premier regard de derriere les barreux: Reflexions a batons rompus. Information Psychiatrique. 66, 653-657.

Bernuz, M.J., Fdz. Molina, E. \& Pérez, F. (2006). El tratamiento institucional de los menores que cometen delitos antes de los 14 años. Revista Española de Investigación Criminológica, 4.

Bernuz, M.J., Fernández, E. \& Pérez, F. (2009). La libertad vigilada como medida individualizadora de la Justicia de Menores. Revista Española de Investigación Criminológica, 7, 1-34.

Chapple, C. L., McQuillan, J. A. and Berdahl, T. A. (2005). Gender, social bonds and delinquency: a comparison of boys' and girls'. Models .Social Science Research, 34, 357-383.

Cid, J. (2008). El incremento de la población reclusa en España 1996-2006: Diagnóstico y remedios. Revista Española de Investigación Criminológica, 6.

Cid, J. \& Tébar, B. (2010). Libertad condicional y delincuentes de alto riesgo. Revista Española de Investigación Criminológica, 8.

Comas, D (2008). Estado de Salud de la Juventud. En Andreu López, Germán Gil, Almudena Moreno, Domingo Comas, $\mathrm{M}^{\mathrm{a}}$ Jesús Funes y Sonia Parella, Informe Juventud en España 2008. Disponible en http://www.injuve.migualdad.es/injuve/contenidos.downloadatt.action?id=54882 $\underline{8853}$. 
Cox, V., Paulus, P., y McCain, G. (1984). Prison Crowding Research. American Psychologist, 39,10.

Cubells, J. \& Iñiguez, L. (2008). La construcción de los hechos en el discurso jurídico: Análisis del caso de los robos en cajeros automáticos en la ciudad de Barcelona. Revista Española de Investigación Criminológica, 6, 1-24.

Del Pozo, M. P. (1987). Creación de un instrumento para evaluar el clima social en prisión. Revista de Estudios Penitenciarios, 238, 115-118.

Díez-Repollés, J.L. (2006). Algunos rasgos de la delincuencia en España a comienzos del s. XXI. Revista Española de Investigación Criminológica, 4.

Díez-Repollés, J.L. \& Gómez-Céspedes, A. (2008). La corrupción urbanística: Estrategias de análisis. Revista Española de Investigación Criminológica, 6

Ellis, J. (1989). Iron bars doth a prison make: Description of a correctional setting. Behavior Analysis and Social Action. 7, 4-9.

Fernández, E \& Rechea, C. (2006). ¿Un sistema con vocación de reforma?: La ley de Responsabilidad penal de los Menores. Revista Española de Investigación Criminológica, 4, 1-34.

Fernández, E. Bartolomé, R., Rechea, C. \& Megías, A. (2009). Evolución y tendencias de la delincuencia juvenil en España. Revista Española de Investigación Criminológica, 7, 1-30.

Fernández-Ramírez, B. y Corraliza, J.A. (1998). Generalidad y especificidad en la explicación del miedo al delito. Apuntes de Psicología, 16(12): 173-186.

Fernández-Ramirez, B. (2008). 6 hipótesis de trabajo para entender la delincuencia y el miedo al delito. Revista Española de Investigación Criminológica, 6.

Foster, N. (2004). Crime, fear and the gate. Prospects of resurgence in South African cities. Presentado en Leverhulme International Symposium 2004: The resurgent city. Londres: London School of Economics, 19-21 de Abril. Recuperado el 25 de Mayo de 2007 desde la página de la London School of Economics and Political Science: http://www.lse.ac.uk/collections/resurgentCity/Papers/NinaFoster.pdf

García-España, E., Díez Ripollés, J.L., Pérez Jiménez, F. Benítez, M.J. \& Cerezo, A. (2010). Evolución de la delincuencia en España: Análisis longitudinal con encuestas de victimización. Revista Española de Investigación Criminológica, 8. 
Gimenez-Salinas, A. \& San Juan, C. (2009). Recensión del libro "Intolerancia cero" de S. Redondo. Revista Española de Investigación Criminológica, 7.

Guimera, A. (2005). La mediación reparación en el derecho penal de adultos. Revista Española de Investigación Criminológica, 3.

Jiménez, J.M. (2002). Niños y madres en prisión: Escenarios de desarrollo familiares y escolares en los centros penitenciarios españoles. Infancia y Aprendizaje, 25, 2, 183-194.

Kaminski, G. (1983). The enigma of ecological psychology. Journal of Environmental Psychology, 3, 85-94.

Larrauri, E. (2010). Los programas formativos como medida penal alternativa en los casos de violencia de género. Revista Española de Investigación Criminológica, 8.

Little (1987) es Little, B.R. (1983). Personal projects: A rationale and method for investigation. Environment and Behavior, 15(3), 273-309.

Little, B.R., Salmela-Aro, K. y Philips, S.D., eds. (2006). Personal Project pursuit. Goals, action, and human flourishing. Mahwah, NJ: Erlbaum.

López, C. (2003). ¿Lucha contra la criminalidad mediante el cumplimiento íntegro y efectivo de las penas?. Revista Española de Investigación Criminológica, 1.

López, M.J. \& Núñez, M.C. (2009). Psicopatía versus trastorno antisocial de la personalidad. Revista Española de Investigación Criminológica, 7.

Luque, E., Ferrer- M. y Capdevila. M. (2004). La reincidència penitenciaria a Catalunya. Barcelona: Centre d'Estudis Jurídics i Formació Especialitzada.

Neisser (1976). Cognition and Reality. San Francisco, CA: Freeman.

Manzanos, C. (2003). Situación de las mujeres en las cárceles del País Vasco. Vitoria: Servicio de Publicaciones del Gobierno Vasco.

Marteache, N., Martínez, M. \& Pérez, M. (2010). Comparación entre opinión pública y “opinión pública meditada" en relación a la delincuencia sexual. Revista Española de Investigación Criminológica, 8.

Martín, V.M. (2008). Estudio socio-educativo de los jóvenes internados en las prisiones andaluzas. Revista Española de Investigación Criminológica, 6, 1-25.

Martín-Segura, A. \& Navarro, J.L. (2007). Metodología econométrica para el análisis económico del delito: Los modelos de datos de panel. Revista Española de Investigación Criminológica, 5. 
Martínez, C., y Arrópide, J. (1996). La intervención psicosocial como medio de creación de ámbitos grupales en contextos en crisis. . En C. San Juan (Coord.): Intervención Psicosocial: elementos de programación y evaluación socialmente eficaces. Barcelona: Anthropos.

Mateu-Gelabert, P. (2004). Sueños, bandas y pistolas: La interacción entre violencia adolescente y la inmigración en un vecindario de la ciudad de Nueva York. Revista Española de Investigación Criminológica, 2, 1-30.

Milgram, S. (1970). The experience of living in cities. Science, 167, 1461-1468.

Mucchielli, L. (2010). ¿Vivimos en una sociedad más violenta?. Revista Española de Investigación Criminológica, 8.

Piquero, A. R., Farrington, D. P. \& Blumstein, A. (2003). The criminal career paradigm. En M. Tonry (Ed.), Crime and justice: A review of research, 30, 359-506. Chicago: University of Chicago Press.

Redondo, S., Roca, M., Pérez, E., y Sánchez, A. (1990). Diseño ambiental de una prisión de jóvenes: Cinco años de evaluación. Delincuencia. 2, 331-357.

Redondo, S. (2008): Individuos, sociedades y oportunidades en la explicación y prevención del delito. Revista Española de Investigación Criminológica, 6.

Rodgers, D. (2004). Haciendo del peligro una vocación: La antropología, la violencia y los dilemas de la observación participante. Revista Española de Investigación Criminológica, 2, 1-24.

Rodriguez, A. (2003). Los determinantes socio-económicos del delito en España. Revista Española de Investigación Criminológica, 1.

Rodríguez Sanabra, F. (1986). Percepción ambiental. En F. Jiménez Burillo y J.I. Aragonés (Eds.), introducción a la Psicología ambiental (pp. 21-34). Madrid: Alianza.

San Juan, C., Vergara, A. y Germán, I. (2005). Propiedades psicométricas de un cuestionario para la evaluación de la calidad de vida urbana y el miedo al delito. Revista Española de Investigación Criminológica, 3, 1-13.

Sancha, V., y García, J. (1987). Tratamiento psicológico penitenciario. Papeles del Colegio de Psicólogos. 5, 27-42.

Shaw, C. y McKay, H. (1942). Juvenile Delinquency and Urban Areas. Chicago: University of Chicago Press.

Smyth, N., y Ivanoff, A. (1994). Maladaptation and prison environmental preferences 
among inmate parasuicides. Journal of Offender Rehabilitation. 20, 131-146.

Soria, M.A. \& Armadans, I. (2008). Las pruebas periciales: Tipologías y relación con las distintas causas judiciales penales. Revista Española de Investigación Criminológica, 6.

Summers, L. \& Johnson, S. \& Pease, K. (2007). El contagio de robos de vehículos y sustracciones de objetos en vehículos: Aplicaciones de técnicas epidemiológicas. Revista Española de Investigación Criminológica, 5.

Swaaningen, René van (2004): 'Veiligheid in Nederland in Europa: een sociologische beschouwing aan de hand van David Garland', en: Justitiële Verkenningen vol.30, no.7, pp. 9-23.

Swaaningen, R. (2005). La política de seguridad ciudadana en Holanda: Traficando con el miedo. Revista Española de Investigación Criminológica. 3, 1-21

Swanningen, R. (2007). Barriendo las calles: Sociedad civil y seguridad ciudadana en Rótterdam. Revista Española de Investigación Criminológica. 5, 1-21.

Sykes, G. (1978). La manera en que el ambiente transmite el estatus de preso. En H. M. Proshansky, W. H. Ittelson y L. G. Rivlin (Eds.): Psicología Ambiental. México: Trillas.

Taylor, R.B. (1987). Toward an environmental psychology of disorder: delinquency, crime, and fear of crime. En D. Stokols e I. Altman (Eds.), Handbook of environmental psychology (951-986). Nueva York: Wiley.

Valverde, J. (1991). La cárcel y sus consecuencias: La intervención sobre la conducta desadaptada. Madrid: Editorial Popular.

Varona, D. (2008). Ciudadanos y actitudes punitivas: Un estudio piloto de población universitaria española. Revista Española de Investigación Criminológica, 6.

Veitch, R., y Arkkelin, D. (1995). Environmental Psychology. New Jersey: Prentice Hall.

Vozmediano, L. \& San Juan, C. (2006). Empleo de Sistemas de Información Geográfica en el estudio del miedo al delito. Revista Española de Investigación Criminológica, 4.

Weber, M. (1972). Ensayos de sociología contemporánea. Barcelona: Martínez Roca.

Weiler, J. (1999): Girls and violence. New York: ERIC Clearinghouse on Urban Education. ERIC document No ED 430069.

Wener, R.E. \& Keys, C. (2006). The effects of changes in jail population densities on 
crowding, sick call and spatial behavior. Journal of Applied Social Psychology. $18,10,852-866$.

Wolff, K. (1950). The Sociology of Georg Simmel. Nueva York: Free Press.

Wright, K. N. (1993). Prison environmnet and behavioral outcomes. Journal of Offender Rehabilitation. 20, 93-113. 